\title{
Information communication technologies (ICTs) and knowledge sharing: the case of professional accountants in Malaysia
}

\begin{abstract}
Based on the knowledge sharing model by Nonaka (1994), this study examines the relative efficacy of various Information Communication Technologies (ICTs) applications in facilitating sharing of explicit and tacit knowledge among professional accountants in Malaysia. The results of this study indicate that ICTs, generally, facilitate all modes of knowledge sharing. Best-Practice Repositories are effective for sharing of both explicit and tacit knowledge, while internet/e-mail facilities are effective for tacit knowledge sharing. Data warehousing/mining, on the other hand, is effective in facilitating self learning through tacit-to-tacit mode and explicit-to-explicit mode. ICT facilities used mainly for office administration are ineffective for knowledge sharing purpose. The implications of the findings are discussed.
\end{abstract}

Keyword: ICTs; Information communication technologies; Knowledge sharing; Explicit knowledge; Tacit knowledge; Professional accountants 